Research Article

\title{
Experimental Study on Mechanical Properties of Interface between Basalt Fiber-Reinforced Polymer/Glass Fiber-Reinforced Polymer Composite Cement Plate and Concrete
}

\author{
Lifeng Zhang $\mathbb{D},{ }^{1}$ Hui Liu $\mathbb{D},{ }^{1}$ Wenqiang Li $\mathbb{D}^{1},{ }^{1}$ Hangjun Liu $\mathbb{D}^{1},{ }^{1}$ Xuehui An $\mathbb{D}{ }^{2}$ \\ and Xiaoruan Song ${ }^{3}{ }^{3}$ \\ ${ }^{1}$ Power China Road Bridge Group, Beijing 100048, China \\ ${ }^{2}$ School of Civil Engineering, Tsinghua University, Beijing 100084, China \\ ${ }^{3}$ Department of Civil Engineering, North China University of Technology, Beijing 100144, China
}

Correspondence should be addressed to Hui Liu; lqliuhui@powerchina.cn and Xiaoruan Song; sxr@ncut.edu.cn

Received 29 October 2020; Revised 22 December 2020; Accepted 3 March 2021; Published 17 March 2021

Academic Editor: Jinyang Xu

Copyright (C) 2021 Lifeng Zhang et al. This is an open access article distributed under the Creative Commons Attribution License, which permits unrestricted use, distribution, and reproduction in any medium, provided the original work is properly cited.

\begin{abstract}
The bonding behaviors of the plate-concrete interface of a composite structure consisting of a concrete block in the middle and two cement plates at both sides play a key role in its overall mechanical performance. In this paper, the authors conduct 3 groups of push-out shear tests on a total of 39 composite samples to assess the bonding performance. The influence of the FRP cement plates, the concrete strength, and the ribs installed in the cement plate on the interfacial shear strength, the relative bond-slip, strain, and the failure modes of the composite samples is recorded and analyzed. The results show that (1) the shear strength and bond-slip performance of the interface are largely improved if the GFRP/BRRP cement plates are used; (2) shear strength of the interface increases with the concrete strength, while the deformation behaviors show no significant improvement; (3) an inclusion of the ribs to the interface enhances the shear strength and shear stiffness but decreases the maximum relative slip at failure; (4) most of the samples present the shear failures along the interface; however, the bending shear failure prior to the interface shear failure is also observed on the concrete block for low concrete strength samples and the samples with ribs; and (5) regression method is used to develop a constitutive model of the stress-slip at the interface to describe the relationship between the shear strength with the cement plates, the concrete strength, and ribs.
\end{abstract}

\section{Introduction and Background}

The fiber-reinforced polymer (FRP) material has become one of the most popular construction materials and has been widely used in civil engineering in recent years $[1,2]$. As compared to traditional materials, the FRP material has higher strength, lighter weight, easier construction procedures, and more reliable performance. Of the FRP materials, the glass fiber-reinforced polymer (GFRP) and the basalt fiber-reinforced polymer (BFRP) are two of the most commonly used fiber materials. The lightweight GFRP has a long service life, good corrosion resistance, and many other advantages. The electric-insulating BFRP also shows good resistance to corrosion as well as to high temperature $[3,4]$. Both the two types of new FRP materials have become the most important materials in structure strengthening engineering $[5,6]$.

This paper has utilized the BFRP/GFRP materials for the construction of a composite structure. The composite structure consists of a concrete block in the middle and two FRP reinforced cement plates at both sides (see Figure 1). The cement plate is reinforced with the fiber mesh and can be used as a permanent mold/plate. The concrete is poured between the two permanent plates during construction; thus, a composite structure is easily created. As compared to the traditional cement plates, the permanent composite plate offers advantages in terms of the overall costs, the construction period, and materials saving including steel, wood, and bamboo. It also saves demolding operations and transportation cost. As a composite structure, both the 


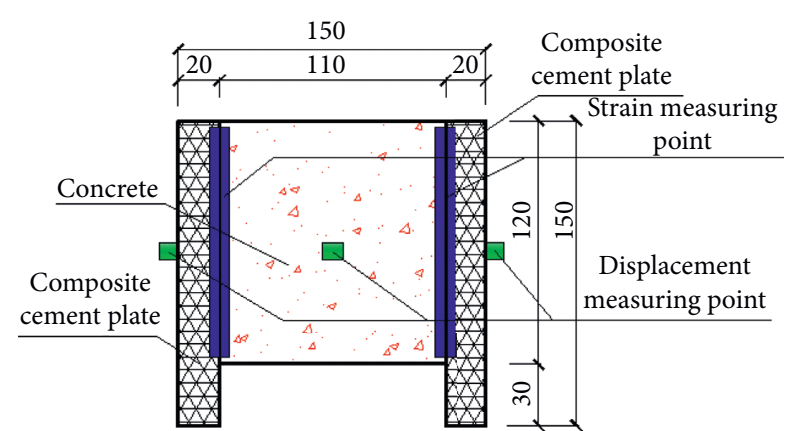

Figure 1: A schematic of the composite sample showing the structure and geometry.

middle concrete and the reinforced composite cement plates at two sides can sustain loads, and therefore, the overall mechanical performance is improved. However, the bonding performance between the reinforced permanent plates and concrete becomes the major concern for this composite structure.

From the field application of the composite structures, it is observed that the early separation of the FRP reinforced cement plates from the concrete block greatly impairs the load-bearing capacity of the composite structure. Therefore, extensive studies have been made to investigate the bonding behaviors of the concrete-plate interface. Ma et al. performed the simple shear tests to study the bonding properties of a concrete beam reinforced by CFRP sheets under the cyclic loading condition [7]. They found that the length and thickness of the CFRP sheets and the concrete grade have a major impact on the bonding between the CFRP sheets and the concrete and that a larger loading rate reduces the fatigue endurance of the interface. Chen et al. reinforced the manually precracked single trabeculae by attaching FRP sheets on its sides and tested the bonding performance [8]. The influence of dimensions of the FRP sheets and the applied loading conditions were included in their work. Nanni et al. studied the interfacial bonding performance of the interface between FRP reinforced laminated plates and the middle concrete and found that the stiffness of the laminated plate significantly impacts the failure load of the interface [9]. Nakaba et al. proposed a constitutive model to describe the relationship between the local bond stress and the slip at the interface between the FRP reinforced laminated plate and the concrete based on a number of double shear tests [10]. Li et al. performed the simple shear tests on the concrete samples with embedded CFRP sheets [11]. The length of the embedding CRFP sheets was found to have a great influence on the bonding behaviors.

Other researchers improved the bonding performance of the composite structures by material modification and the connection modes at the interface. Gravina et al. investigated the bonding behavior between the FRP laminated sheets preimpregnated with resin [12]. The resin was also used for concrete modification and the thickness of the bonding interface was included in their experiment to study the adhesive performance of the composite structure. The material modification can improve the bonding force. Zhou et al. improved the bonding properties of the composite structure by increasing the mechanical fastening pressures between the FRPconcrete interfaces [13]. Chen et al. designed a horizontal slot at the interface to improve the bonding and deformation capacity of the composite structure [14]. Studies on the endurance of the interface were also documented in previous works. Wang et al. concluded that the bonding force between the FRP plates and the concrete was reduced when subjected to water, seawater, high temperature, the cyclic damp heat condition, and the corrosion under acid and alkali conditions [15]. They found from their tests that the high temperature presented worse deterioration to the interface properties than the low temperature and the presence of mortar joint in the composite structure further reduced the bonding capacity of the interface. The endurance of the composite structure interface under the extreme weather and loading conditions was included in Wang et al. [16].

The bonding between the FRP cement plates and the concrete is the key factor largely determining the overall performance of the composite structures. A number of researchers have developed the constitutive models to describe the bonding stress and slip deformation at the interface. Lin and Cao investigated the bonding performance at the pure bending section of the CFRP concrete structure and developed an analytical model to describe the bond and slip behaviors at the interface [17]. Woo and Yun conducted the pull-out tests to composite structures with CFRP sheets attaching to the concrete and developed their constitutive model from back analysis [18]. Baky et al. and Dai et al. analyzed the seismic performance of an FRP reinforced dam using a nonlinear bond-slip model [19, 20]. Wang et al. updated their constitutive model based on a beam test on the CFRP composite structures [21]. Gao et al. proposed a continuous curved bonding-slip model based on a summary of the previous constitutive models [22]. Lu et al. developed a bonding-slip constitutive model with a consideration of the interface stiffness [23]. The model was used to predict the separation of the interface. Ko et al. conducted the double shear tests on 18 composite samples to investigate the bonding between the GFRP sheets and the concrete, based on which a bilinear stress-slip model was proposed [24]. Hao et al. performed the pull-out tests to study the bonding between the steel strand and the concrete on 180 samples, with a consideration of the placement of the strand and the dimensions of the concrete [25]. They improved their bondingslip constitutive model based on the experimental results.

The previous studies have improved our understandings of the bonding performance of the composite structures between the FRP materials and the concrete. However, the CFRP and GFRP sheets rather than the FRP cement plates were used for most of the composite structures in previous works. This paper attempts to evaluate the bonding performance between the BFRP/GFRP reinforced cement plates and the concrete block with a consideration of the types of the fiber mesh, the concrete grade, and the inclusion of steel ribs in the cement plates. Three sets of experiments were designed and were used to conduct the push-out tests in the present work. The first set compares the bonding performance of the composite structures with three different cement 
plates, that is, the regular cement plates for the GS samples, the BFRP reinforced plates for the GB samples, and the GFRP reinforced plates for the DG samples. The second set consists of different composite structures made of the C15, C30, and C50 concrete. The third set includes the composite samples with and without ribs to investigate the influence of the mechanical interaction at the interface. The failure characteristics of the composite samples and the relation between the shearing capacity and the slip deformation at the interface were recorded. The shearing strength as a function of the slip deformation was obtained using the regression approach. The results from this paper may provide a reference for improving the bonding performance and promoting the industrial applications of the composite structures.

\section{Experiment Design}

2.1. Sample Preparation. In this research, the push-out shear test is performed to study the influence of the fiber-reinforced cement plate, concrete strength, and ribs in the plate on the bonding performance of the plate-concrete interface. Figure 1 gives a front view of the composite structure. The cement plate at both ends is $20 \mathrm{~mm}$ thick, $150 \mathrm{~mm}$ high, and $150 \mathrm{~mm}$ long, and the middle concrete body is $110 \mathrm{~mm}$ thick, $120 \mathrm{~mm}$ high, and $150 \mathrm{~mm}$ long. Therefore, the overall dimension of the composite specimen prepared in this study is $150 \times 150 \times 150 \mathrm{~mm}$. Efforts were made during the sample construction to make sure that all specimens have the same size. The concrete is poured $30 \mathrm{~mm}$ above the bottom; thus, the push-out shearing test can be performed.

The cement plate is constructed using cement, fly ash, expanded perlite, sand, water reducing agent, and coupling agent with a proportion of $1: 0.25: 0.015: 0.15: 0.007: 0.015$ by weight. During construction, the GFRP plate uses low alkalinity cement while the BFRP plate uses the Portland cement [26]. Fiber meshes are placed on both side surfaces of the plate. The fiber meshes used in the GFRP and BFRP plates have the same density $\left(160 \mathrm{~g} / \mathrm{m}^{2}\right)$.

The construction of the BFRP and GFRP composite samples includes three procedures: (1) preparation of the experimental mold and cement slabs; (2) concrete pouring between the composite cement plates; and (3) sample curing at room temperature for 28 days. For ease of demolding, the inner surface of the mold was cleaned and coated with lubricating oil before pouring. Two pieces of cement plates are placed at both sides of the mold, and a $30 \mathrm{~mm}$ thick foam block is placed at the bottom between the two plates for reserving space for the later push-out test. The foam is tightly pressed on cement plates to prevent slurry leakage. The concrete is poured at a designed strength (i.e., C15, C30, and C50 in this study) for comparing the concrete strength influence on the bonding behaviors of the plate-concrete interface. After demolding, the composite samples are cured for a period of 28 days at room temperature.

2.2. Loading Condition and Data Measuring System. The push-out shearing test is performed on a compression testing machine. Figure 2 plots the loading condition of the

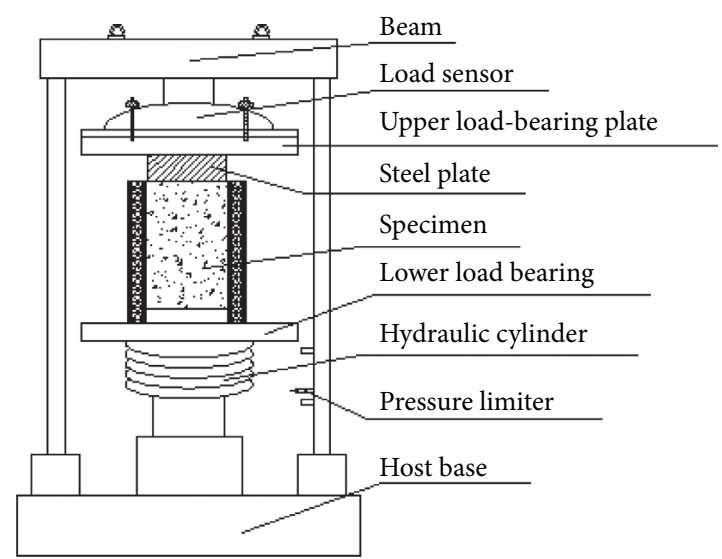

FIgURE 2: A schematic of the loading condition of the composite sample.

composite sample. The composite sample is placed between the upper and lower bearing plates. A steel plate slightly less than $110 \mathrm{~mm}$ wide is put between the upper bearing plate and the sample for performing the push-out shearing test. The test is ceased when the sample is damaged.

The bonding performance of the plate-concrete interface (including the shear strength and relative bond-slip) is the major concern of this study. The layout of the measuring points is also shown in Figure 1. A total of 3 displacement measuring points can be found on the left and right sides of the two plates and on the front surface of the concrete body, respectively. The relative slip of the plate-concrete interface can therefore be obtained. The strain data of the interface, however, were measured by 2 strain gauges placed at the plate-concrete boundaries. The testing machine (type SANS) is used to load, the sensor (type CFBLY) is used to record the load data, and the data acquisition system (type BETC) is used to collect data. The shear stress, relative movement, and strain data of the interface are recorded during the test. The failure characteristics and development of fractures on the sample are also observed by a camera.

2.3. Material Strength Test. In the process of making specimens, the concrete samples with different strength grades are reserved, which are $150 \mathrm{~mm} \times 150 \mathrm{~mm} \times 150 \mathrm{~mm}$. The ordinary plain cement board samples, BFRP reinforced cement composite board samples, and GFRP reinforced cement composite board samples are all reserved for material mechanics tests, which are $20 \mathrm{~mm} \times 250 \mathrm{~mm} \times 250 \mathrm{~mm}$. The compressive strength of concrete is shown in Table 1. The flexural strength of the cement board is shown in Table 2 .

\section{Results and Analysis}

3.1. Effect of Fiber Mesh Type on Interface Bonding Performance. As mentioned above, the inclusion of fiber mesh in the cement plate and its type should influence the bonding performance of the plate-concrete interface. Therefore, the first group of tests compares the influence of three kinds of cement plates, that is, the plain Portland 
TABLE 1: The 28-day compressive strength of concrete.

\begin{tabular}{lc}
\hline Concrete type & Average compressive strength $(\mathrm{MPa})$ \\
\hline C15 & 15.3 \\
C30 & 31.1 \\
C50 & 51.2 \\
\hline
\end{tabular}

TABLE 2: The flexural strength of cement board.

\begin{tabular}{lc}
\hline Cement board type & $\begin{array}{c}\text { Average flexural } \\
\text { strength (MPa) }\end{array}$ \\
\hline Plain cement board & 5.4 \\
BFRP reinforced cement composite board & 12.1 \\
GFRP reinforced cement composite board & 12.3 \\
\hline
\end{tabular}

cement plate without fiber reinforcement (GS); BFRP reinforced ordinary Portland composite cement plate (GB), and GFRP reinforced low alkalinity composite cement plate (DG). All the three sets of composite specimens utilize C30 for the middle concrete during the sample preparation. In each set, 3 samples are prepared. Therefore, the total number of samples in this group is 9. The samples are assigned with different numbers for better analysis. Sample GS C30-1, for instance, represents the first sample with the GS cement plates on both sides and C30 middle concrete.

3.1.1. Failure Modes of Specimens. Figure 3 shows the failure characteristics of the samples after the shear test. It is found that all 3 GS samples present brittle failure (see Figure 3(a)). Of those, samples GS C30-1 and GS C30-3 show both shear failure along the interface and failure on the cement plate, and sample GS C30-2 only finds brittle failure and fractures on the cement plate. All the failures occur on the relatively weak side of the sample. For the $3 \mathrm{~GB}$ samples, the shear failure along the interface is found on both GB C30-2 and GB C30-3 samples, while GB C30-1 sees failure in the concrete body (Figure 3(b)). By contrast, all three DG composite samples see shear failure along the interface (Figure 3(c)) and separations between the cement plates and the concrete are observed.

The shearing test reveals that the fiber-reinforced composite sample fails along the plate-concrete interface prior to the cement plate, indicating that the overall loadbearing capacity of the cement plate is largely improved by the fiber materials. The bonding performance of the interface is also enhanced for the fiber-reinforced samples as compared to the nonfiber samples and the interfacial shear strength of the fiber-reinforced sample is even higher than that of C30 concrete itself.

3.1.2. Shear Strength of the Interface. Table 3 compares the shear strength of the plate-concrete interface for the composite samples with different fiber-reinforced cement plates. The shear strength of the nonfiber composite sample (GS samples) is noticeably lower than the fiber-reinforced samples. The mean value of the shear strength for the GS samples is $0.64 \mathrm{MPa}$, which is only $63.63 \%$ and $55.77 \%$ of the
GB (1.00 MPa) and DG (1.14 MPa) composite samples, respectively. Hence, the fiber mesh significantly improves the shear strength of the plate-concrete interface. It is also noted that DG composite samples with GFRP cement plates have a slightly larger shearing performance than the GB samples with BFRP plates.

3.1.3. Relative Bond-Slip of the Interface. Table 4 lists the maximum relative slip of the plate-concrete interface with different fiber meshes. The average displacement values of the GS, GB, and DG composite samples are $0.27,0.54$, and $0.45 \mathrm{~mm}$, respectively. Therefore, the composite samples with fiber-reinforced plates allow a larger relative displacement on the plate-concrete interface compared to the composite samples with nonfiber plates.

Figure 4 plots the relationship of the shearing stress over the relative displacement. It shows that the shearing stresses of the GB and DG composite samples increase at a large and similar rate. The fast growth of shearing stresses ends when the relative displacement is about $0.14 \mathrm{~mm}$. The stresses then reach a plateau and only increase slightly over a large displacement; that is, the interface of the fiber-reinforced samples shows plastic deformation characteristics. The slope of the curve for the GS sample, however, is much lower. Therefore, the fiber-reinforced cement plate also improves the deformation performance of the interface.

\subsubsection{Shearing Stress-Strain Relationship of the Interface.} Table 5 summarizes the maximum and mean strain values of the interface for the 3 sets of samples. It shows that the mean strain value of GS C30 samples is only $10.6 \%$ of GB C30 and $18 \%$ of DG C30 samples. The mean maximum strain of GB C30 samples is 1.7 times that of DG C30 specimen.

The shearing stress-strain curve is given in Figure 5. An approximately linear relationship is observed between the stress and strain for all the three sets of samples. It can also be found from the curves that the GB and DG samples show some plastic behaviors at the later stage, which corresponds to the stress-displacement curves.

\subsection{Effect of Concrete Strength on Interface Bonding} Performance. The bonding performance of the plate-concrete interface is also influenced by the concrete strength. The composite samples in this group use C15, C30, and C50 for middle concrete, respectively. The cement plates at both sides are BFRP reinforced ordinary Portland composite cement plate (GB) and GFRP reinforced low alkalinity composite cement plate (DG). Therefore, this group of experiments prepares 6 sets of tests with 18 samples in total. Each sample is assigned a unique number. For instance, the composite structure with BFRP cement plates and $\mathrm{C} 15$ concrete has 3 samples, that is, GB C15-1, GB C15-2, and GB C15-3.

3.2.1. Failure Modes of Specimens. Figure 6 gives the fracture development and failure characteristics of the samples after the test. Note that the GB C30 and DG C30 samples have 


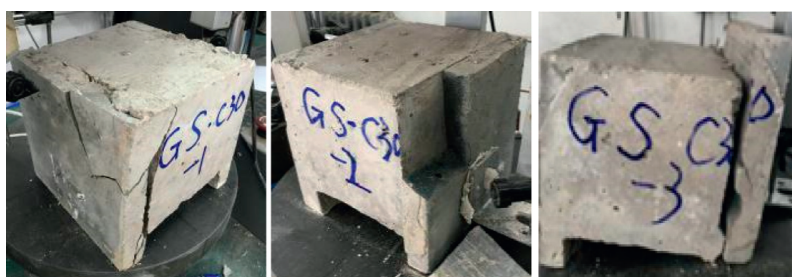

(a)

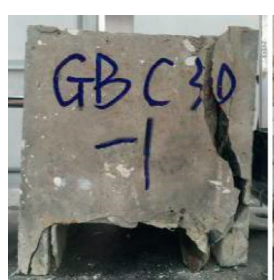

A $x$

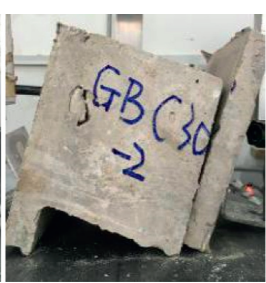

(b)
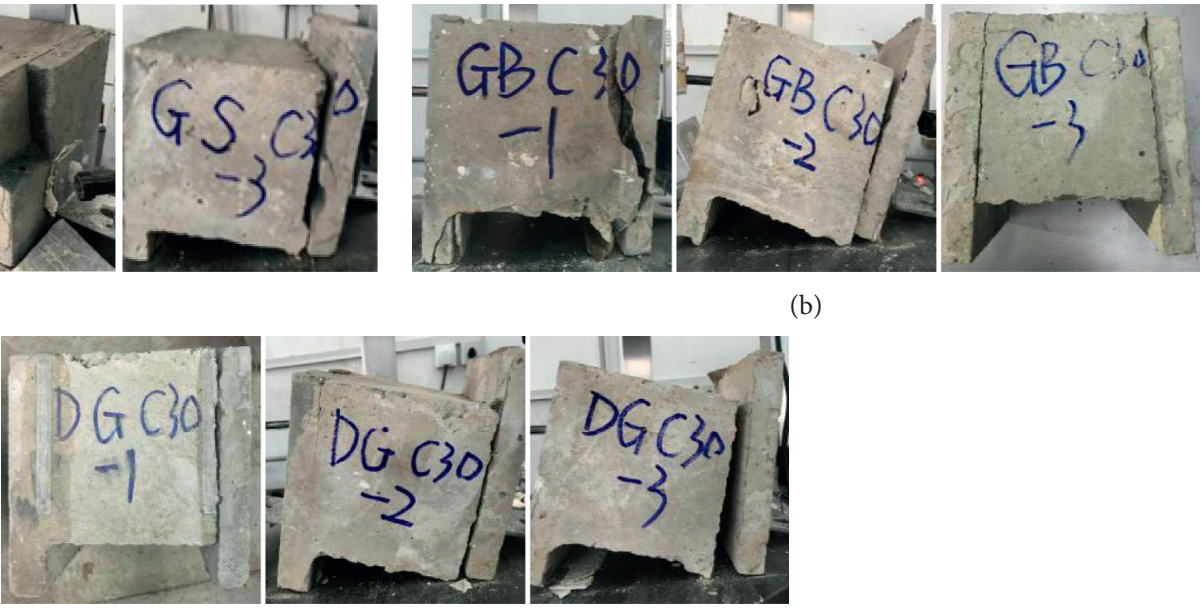

(c)

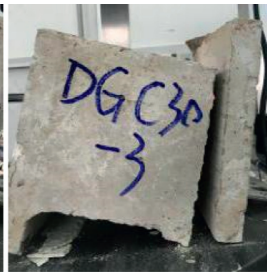

FIGURE 3: Failure characteristics of the composite samples after the shear test: (a) GS C30, (b) GB C30, and (c) DG C30.

TABLE 3: A summary of the shear load at failure and shear strength of the plate-concrete interfaces for samples with different cement plates.

\begin{tabular}{lccccc}
\hline $\begin{array}{l}\text { Composite } \\
\text { sample }\end{array}$ & \multicolumn{6}{c}{ Maximum load at failure, kN } & Shear strength, \\
\hline GS C30 & Sp1 & Sp2 & Sp 3 & Average & MPa \\
GB C30 & 24.33 & 20.84 & 23.75 & 22.97 & 0.64 \\
DG C30 & 41.30 & 30.89 & 36.72 & 36.10 & 1.00 \\
\hline
\end{tabular}

TABle 4: The maximum relative bond-slip of the plate-concrete interfaces at failure for composite samples with different cement plates.

\begin{tabular}{lcccc}
\hline Composite sample & \multicolumn{4}{c}{$\begin{array}{c}\text { Maximum relative displacement at } \\
\text { failure, mm }\end{array}$} \\
& Sp1 & Sp2 & Sp3 & Average \\
\hline GS C30 & 0.257 & 0.276 & 0.265 & 0.266 \\
GB C30 & 0.537 & 0.548 & 0.541 & 0.542 \\
DG C30 & 0.442 & 0.474 & 0.434 & 0.450 \\
\hline
\end{tabular}

been included in Figure 3. Thus, Figure 6 only shows the results of the $\mathrm{C} 15$ and $\mathrm{C} 30$ samples. It is observed that most of the GB samples see shear failure along the interface, except the GB C30-1 and GB C50-3 with failures also observed on the concrete body. GB C30-1 finds failure on both the cement plate and the middle concrete rather than fails in shear along the interface (Figure 3(b)). The GB C50-3 sample, however, finds tensile damage on top of the sample beside the shear failure along the interface (Figure 6(b)).

By comparison, the DG samples show different failure modes. Samples DG C15-1 and C15-3 find tensile failure in the middle concrete due to bending (see Figure 6(c)). The fracture initiates from the bottom of the concrete and extends upwards. Sample DG C15-2, however, sees the common shear failure along the plate-concrete interface; that is, the middle concrete separates from the cement plate when the limit relative displacement is reached. Likewise, all

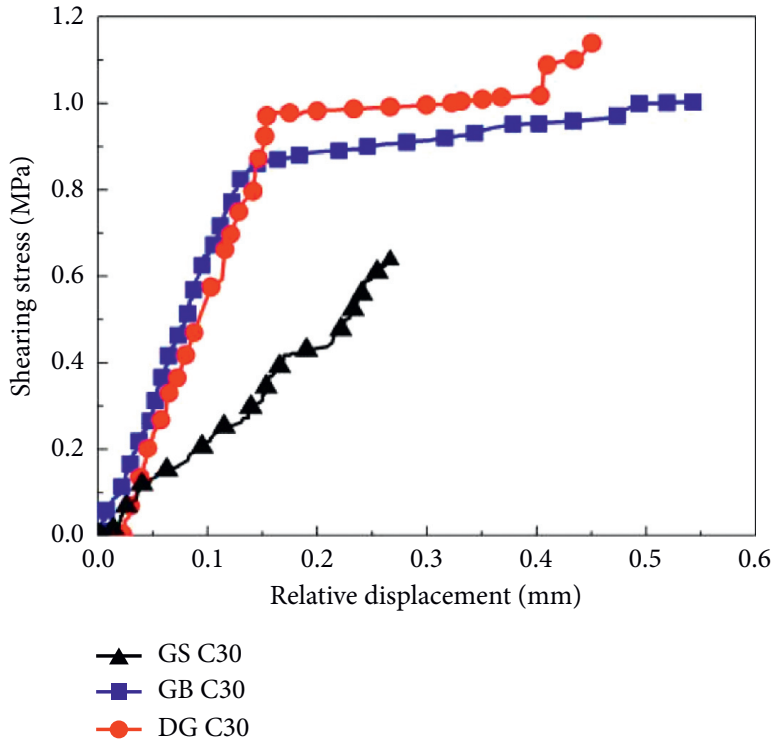

FIGURE 4: Relationship of the shearing stress over the relative displacement of the interface.

TABLe 5: The maximum strain of the interface at failure for composite samples with different cement plates.

\begin{tabular}{lcccc}
\hline \multirow{2}{*}{ Composite sample } & \multicolumn{4}{c}{ Maximum strain, $\mu \varepsilon$} \\
& Sp1 & Sp2 & Sp3 & Average \\
\hline GS C30 & 32.5 & 28.6 & 27.1 & 29.4 \\
GB C30 & 289.4 & 257.8 & 282.6 & 276.4 \\
DG C30 & 168.5 & 157.3 & 162.6 & 162.8 \\
\hline
\end{tabular}

the DG C30 and C50 samples fail in shear along the concrete-plate interface (see Figures 3(c) and 6(d)). The DG C50-3 sample shows a slightly different failure mode, although with the fracture first developing along the interface and then extending to the concrete before cutting through the entire sample. 


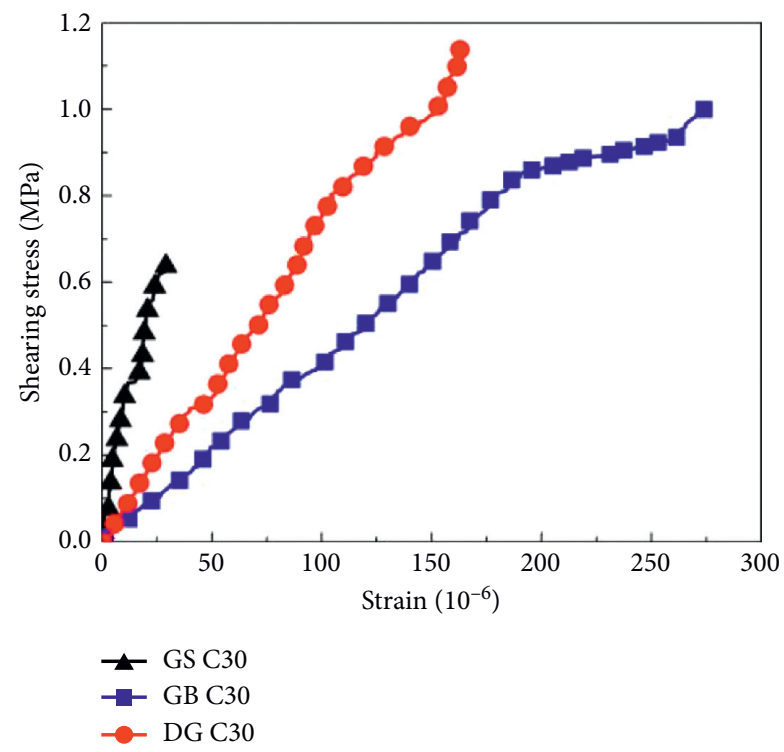

FIGURE 5: Stress-strain curves of the interface for composite samples with different cement plates.
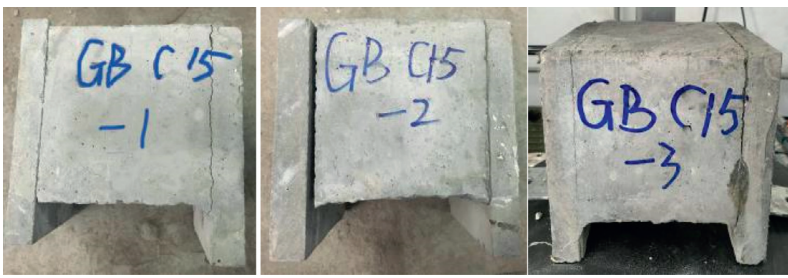

(a)

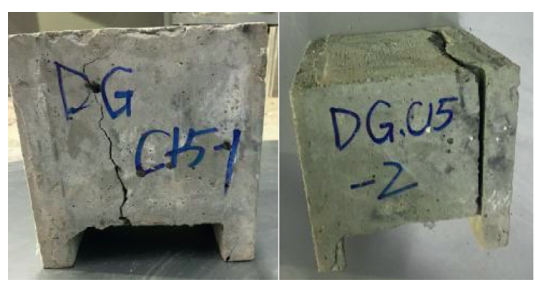

(c)
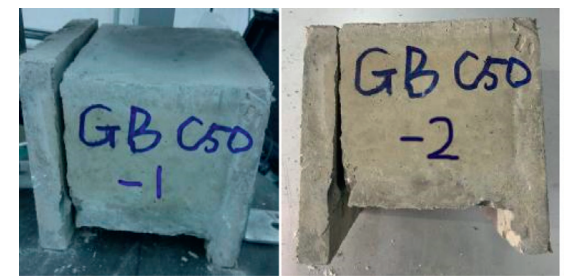

(b)

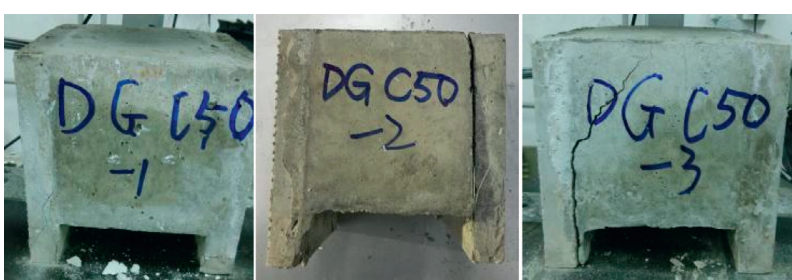

(d)

Figure 6: Failure characteristics of the composite samples after the shear test: (a) GB C15, (b) GB C50, (c) DG C15, and (d) DG C50.

From the above analysis, we learn that most of the failure occurs in shear along the interface. However, it is also interesting to note that bending shear failure in concrete is observed for Samples DG C15-1 and C15-3, and compression shear failure on both cement plate and concrete is found in Sample GB C30-1. In other words, failure in the concrete or cement plate may occur prior to the interfacial shear failure, indicating that the shear strength of the interface may be larger than the cement plate and the concrete body, especially when the concrete strength is low (say, the C15 samples).

3.2.2. Shear Strength of the Interface. Table 6 compares the shear strength of the composite samples with different cement plates and concrete. It shows that the shear strength of the interface increases with the concrete strength for both GB and DG samples. For instance, the shear strength for GB C50 sample is $1.43 \mathrm{MPa}$, which is 1.43 times the GB C30 sample (1.00 MPa) and 2.46 times the GB C15 $(0.58 \mathrm{MPa})$. By contrast, maximum shear strength is found at 1.36 MPa for DG C50, compared to 1.14 MPa for DG C30 and $0.56 \mathrm{MPa}$ for DG C15. On the other hand, the GB and DG samples show no significant discrepancy in the interface shear strength when the same middle concrete is used.

3.2.3. Relative Bond-Slip of the Interface. The maximum relative bond-slip along the concrete-plate interface is provided in Table 7. It is noticed that the relative displacement of the interface shows no significant difference. This differs from the positive relationship between the shear strength and the concrete strength. 
TABLE 6: A summary of the maximum shear load at failure and shear strength of the plate-concrete interfaces for composite samples with different cement plates and concretes.

\begin{tabular}{|c|c|c|c|c|c|c|}
\hline \multirow{2}{*}{ Cement plate } & \multirow{2}{*}{ Concrete } & \multicolumn{4}{|c|}{ Maximum load at failure, $\mathrm{kN}$} & \multirow{2}{*}{ Shear strength, $\mathrm{MPa}$} \\
\hline & & Sp1 & Sp2 & Sp3 & Average & \\
\hline \multirow{3}{*}{$G B$} & $\mathrm{C} 15$ & 19.56 & 22.18 & 18.74 & 20.16 & 0.58 \\
\hline & $\mathrm{C} 30$ & 41.30 & 30.89 & 36.72 & 36.10 & 1.00 \\
\hline & C50 & 52.16 & 50.83 & 51.12 & 51.37 & 1.43 \\
\hline \multirow{3}{*}{$D G$} & $\mathrm{C} 15$ & 20.01 & 21.38 & 21.28 & 20.98 & 0.56 \\
\hline & $\mathrm{C} 30$ & 42.07 & 40.31 & 42.60 & 41.19 & 1.14 \\
\hline & $\mathrm{C} 50$ & 48.79 & 51.23 & 47.01 & 49.07 & 1.36 \\
\hline
\end{tabular}

TABLE 7: The maximum relative bond-slip of the plate-concrete interfaces at failure for composite samples with different cement plates and concretes.

\begin{tabular}{lccccc}
\hline \multirow{2}{*}{ Cement plate } & & \multicolumn{3}{c}{ Maximum relative displacement at failure, mm } \\
& Concrete & Sp1 & Sp2 & 0.513 & Average \\
\hline \multirow{3}{*}{$G B$} & C15 & 0.478 & 0.485 & 0.543 & 0.492 \\
& C30 & 0.537 & 0.546 & 0.516 & 0.542 \\
\hline \multirow{3}{*}{$D G$} & C50 & 0.516 & 0.528 & 0.514 & 0.436 \\
& C15 & 0.487 & 0.499 & 0.451 & 0.450 \\
& C30 & 0.463 & 0.469 & 0.477 \\
\hline
\end{tabular}

Figure 7 plots the shearing stress-relative displacement curves for composite samples with different cement plates and concretes. The deformation behavior along the interface shows different characteristics for samples with different concrete strength, although the maximum relative displacements are generally the same. It shows that the shearing stress for C30 and C50 samples increases rapidly at the early stage of loading, which means the samples pick up the shear load quickly but at a small displacement. After the relative displacement reaches about $0.14 \mathrm{~mm}$, the C30 and C50 samples reach a plateau and show clear plastic deformation behavior, with a large amount of displacement but a small increase in shearing stress. By comparison, the C15 sample shows an approximately linear relationship between the shearing stress and the displacement. It is also observed from the slope of the curves that the overall shearing stiffness of the composite samples is increased with the increase of concrete strength.

3.2.4. Shearing Stress-Strain Relationship of the Interface. Table 8 gives the maximum and mean values of the interface strain. Figure 8 shows the shearing stress-strain curves. It is observed that the interfacial shearing stiffness and deformation performance for both GB and DG samples are increased with enhanced concrete strength. In particular, the C50 samples show obvious plastic displacement behavior at the late stage of loading. The maximum strain, however, does not show a specific relationship with relation to the concrete strength. This is consistent with the results of the interface slip test, which shows that the interface deformation properties can also be reflected by measuring the interfacial strain.
3.3. Effect of Rib on Interface Bonding Performance. The addition of ribs in the cement plate and its layout are also influential to the bonding performance of the plate-concrete interface. The authors have designed cement plates with horizontal (HL) and vertical (ZL) ribs, which are compared to the nonrib samples (WL). The rib is $10 \mathrm{~mm}$ in width and $5 \mathrm{~mm}$ in height. A total of 2 ribs are symmetrically placed in the cement plate with a spacing of $100 \mathrm{~mm}$. During construction, the BFRP (GB) and GFRP (DG) materials are used for cement plates and C30 for concrete. The sample ID is assigned to each sample. Sample GB HL-1 represents the first sample with BFRP cement plate and HL rib.

3.3.1. Failure Modes of Specimens. Figure 9 plots the failure characteristics of the samples after the test. All the $3 \mathrm{~GB} \mathrm{HL}$ samples see shear failure near the plate-concrete interface in both the cement plate and the concrete (Figure 9(a)). This differs from the smooth shear failure of the interface and complete separation of the plate and concrete for the WL samples. The GB ZL samples also see shear failure along the plate-concrete interface (Figure 9(b)). However, fractures extend towards the middle concrete and damage is found in the concrete at top of the sample, especially for the GB ZL-3 sample.

Shear failure along the interface is observed for Samples DG HL-1 and DG HL-2 (Figure 9(c)). The middle concrete for Sample DG HL-1 also sees shear failure near the failure interface side at the top. DG HL-3, however, fails in bending shear in the concrete. The bending shear crack initiates from the bottom and extends upward to the top surface, but the interfaces on both sides still remain intact. Similar to the GB ZL samples, the DG ZL samples find shear failure along the interface and splitting failure on the concrete at the top. 


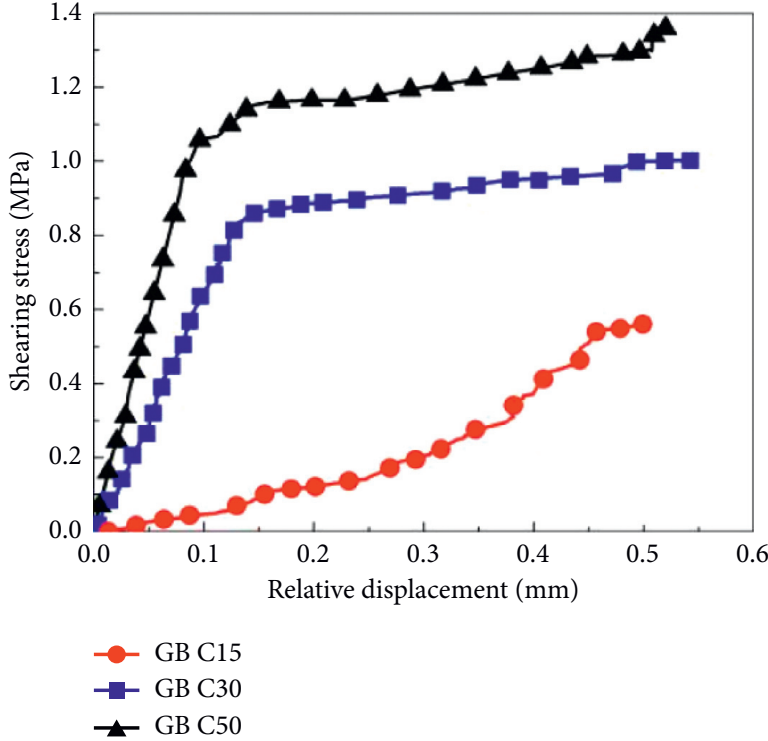

(a)

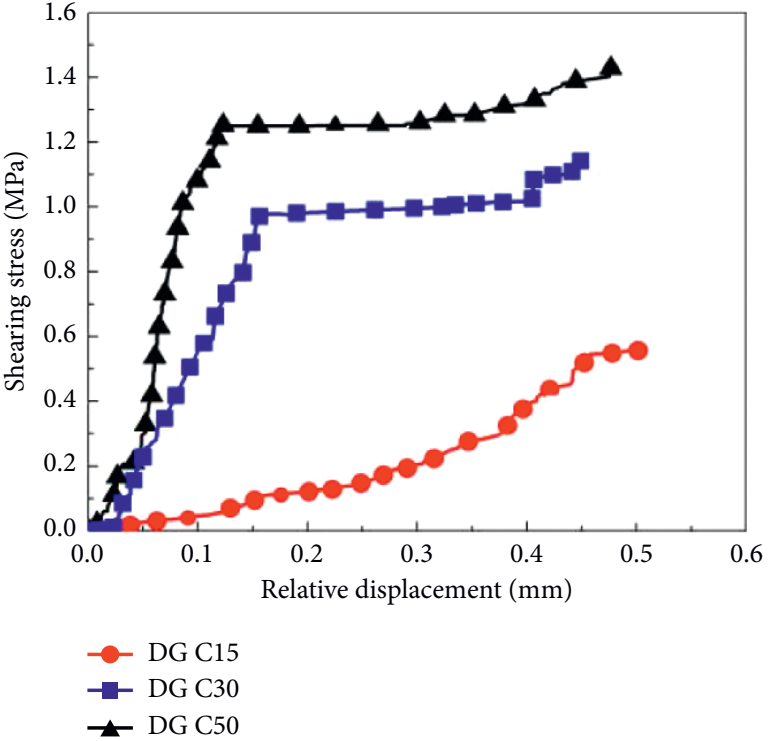

(b)

FIgURE 7: Relationship of the shearing stress over the relative displacement of the interface: (a) GB and (b) DG.

TABLE 8: Maximum strain of the interface at failure for composite samples with different cement plates and concretes.

\begin{tabular}{|c|c|c|c|c|c|}
\hline \multirow{2}{*}{ Cement plate } & \multirow{2}{*}{ Concrete } & \multicolumn{4}{|c|}{ Maximum strain, $\mu \varepsilon$} \\
\hline & & Sp1 & $\mathrm{Sp} 2$ & Sp3 & Average \\
\hline \multirow{3}{*}{$G B$} & $\mathrm{C} 15$ & 118.7 & 136.5 & 106.0 & 120.4 \\
\hline & $\mathrm{C} 30$ & 289.4 & 257.8 & 282.6 & 276.4 \\
\hline & $\mathrm{C} 50$ & 231.5 & 219.3 & 233.5 & 228.1 \\
\hline \multirow{3}{*}{$D G$} & $\mathrm{C} 15$ & 187.3 & 210.2 & 198.9 & 198.8 \\
\hline & $\mathrm{C} 30$ & 168.5 & 157.3 & 162.6 & 162.8 \\
\hline & $\mathrm{C} 50$ & 254.3 & 259.4 & 259.7 & 257.8 \\
\hline
\end{tabular}

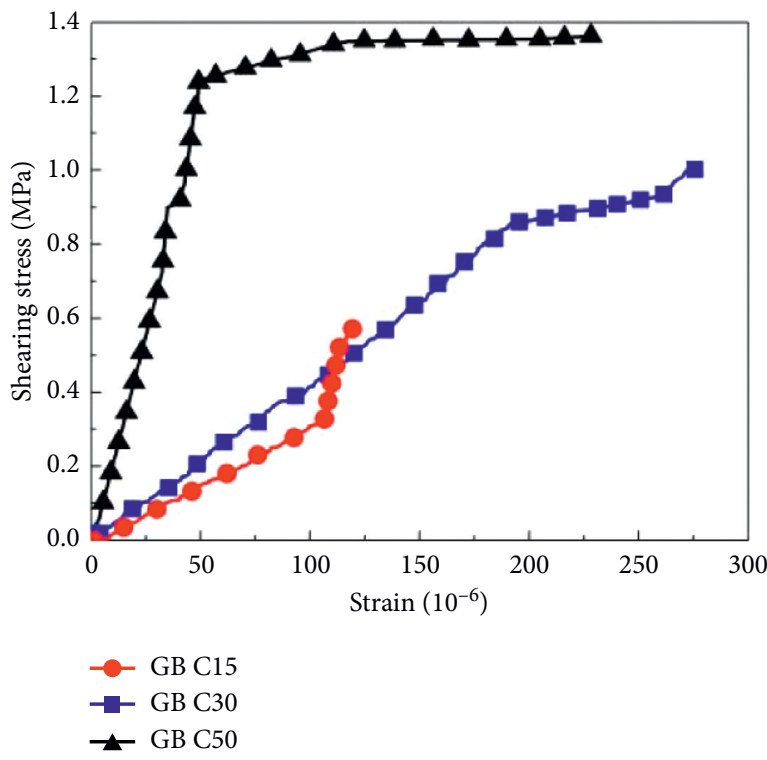

(a)

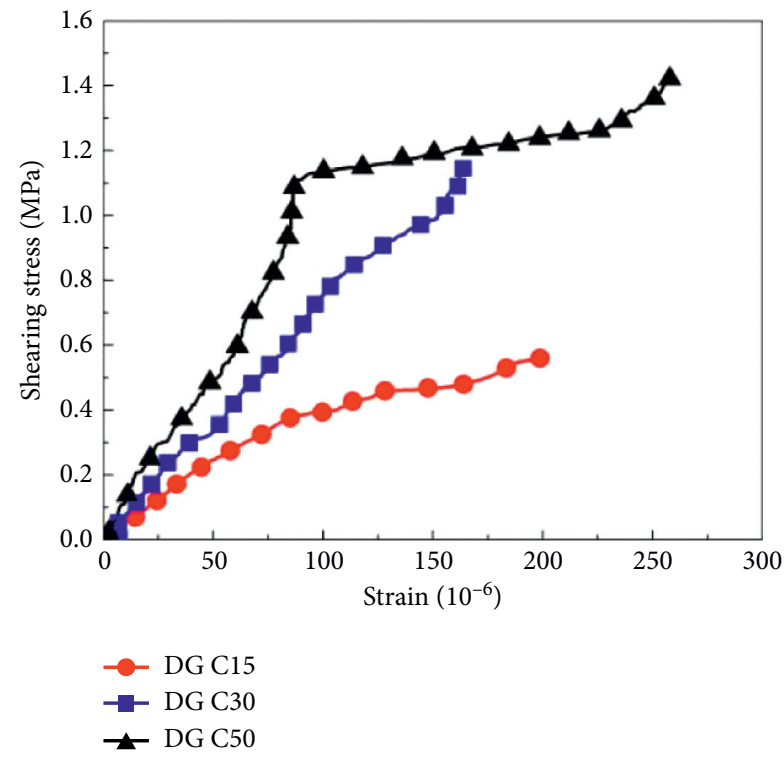

(b)

FIGURE 8: Stress-strain curves of the interface for composite samples with different cement plates and concretes: (a) GB and (b) DG. 


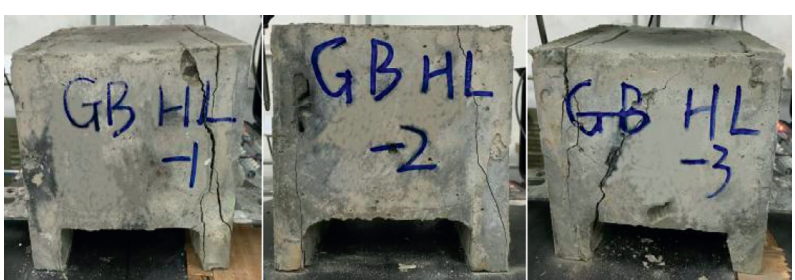

(a)

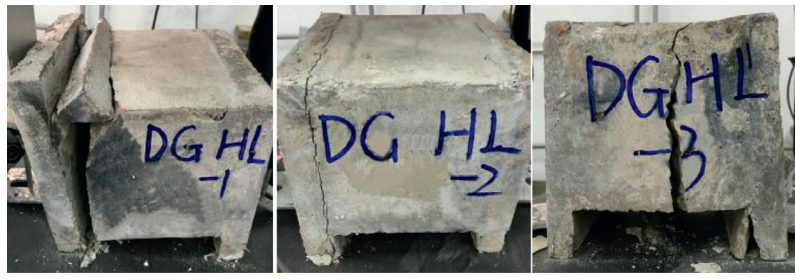

(c)
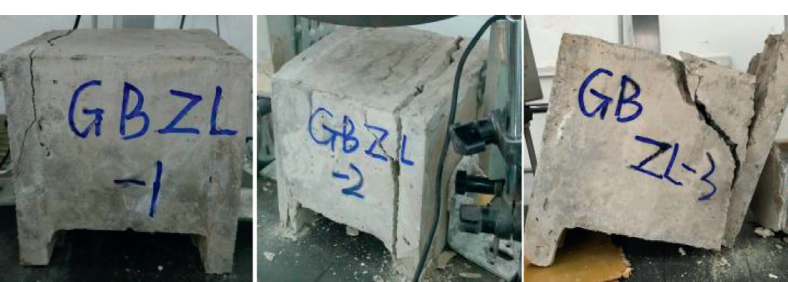

(b)
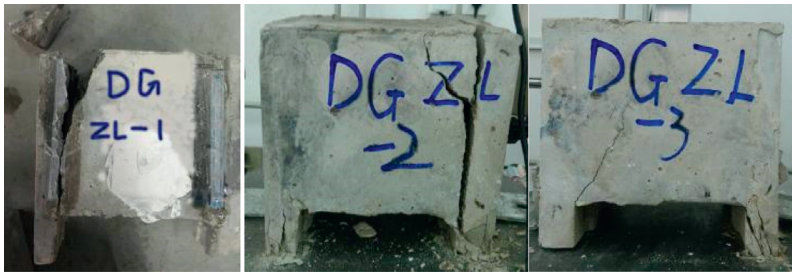

(d)

FIGURE 9: Shear fracture of cement plate and concrete composite specimens with different ribs: (a) GB HL, (b) GB ZL, (c) DG HL, and (d) DG ZL.

Sample DG ZL-3, however, shows an inclined compression shear failure mode with a $45^{\circ}$ fracture (in relation to the interface) developing upward obliquely from the bottom edge (Figure 9(d)).

3.3.2. Shear Strength of the Interface. Table 9 summarizes the maximum shear load of the interface and the shear strength at failure. It is obvious that the samples with ribs in the plate present much larger shear strength than the nonrib ones. The shear strength values for the rib samples almost double those for the nonrib. This is because the presence of ribs in the cement plate not only increases the bonding area but also improves the load transmission between the cement plate and the concrete. The ribs provide extra mechanical interaction at the interface rather than the pure friction for WL samples. Therefore, the ribbed samples are more reliable.

It is also noted that the samples with HL ribs have better interface bonding performance compared to the samples with ZL ribs. The HL ribs play a more important part than the ZL ribs in improving the mechanical interaction at the interface.

3.3.3. Relative Bond-Slip of the Interface. The maximum relative bond-slip of the interface is listed in Table 10 and the curve of the interfacial shear stress-relative displacement is shown in Figure 10. It can be seen that, due to the mechanical interlocking between the rib and the concrete, not only is the interfacial shear bearing capacity of the composite samples increased, but also the interfacial shear stiffness of the composite samples is greatly increased, the HL rib samples present the largest shearing stiffness. The maximum interface slip of the samples after being ribbed is significantly reduced. The sample with HL ribs has the lowest relative displacement, followed by the ZL rib sample and the WL sample. It is also observed that no plastic deformation behavior is found for the rib samples.
TABLE 9: Maximum load at failure and the shear strength of the interface for composite samples with different ribs.

\begin{tabular}{lcccccc}
\hline $\begin{array}{l}\text { Cement } \\
\text { plate }\end{array}$ & Rib & \multicolumn{6}{c}{ Maximum load at failure, kN } & Shear strength, \\
& & Sp1 & Sp2 & Sp3 & Average & MPa \\
\hline \multirow{4}{*}{ GB } & HL & 84.10 & 83.88 & 83.78 & 83.92 & 2.33 \\
& ZL & 75.40 & 72.89 & 76.23 & 74.84 & 2.08 \\
& WL & 41.30 & 30.89 & 36.72 & 36.10 & 1.00 \\
\hline \multirow{4}{*}{$D G$} & HL & 90.01 & 89.62 & 87.55 & 89.06 & 2.47 \\
& ZL & 76.34 & 79.21 & 76.86 & 77.47 & 2.15 \\
& WL & 42.07 & 40.31 & 42.60 & 41.19 & 1.14 \\
\hline
\end{tabular}

TABle 10: Maximum relative bond-slip of the plate-concrete interfaces at failure for composite samples with different ribs.

\begin{tabular}{lccccc}
\hline \multirow{2}{*}{ Cement plate } & \multirow{2}{*}{ Rib } & \multicolumn{4}{c}{ Maximum relative displacement, mm } \\
& & Sp1 & Sp2 & Sp3 & Average \\
\hline \multirow{3}{*}{$G B$} & HL & 0.123 & 0.119 & 0.130 & 0.124 \\
& ZL & 0.249 & 0.267 & 0.249 & 0.255 \\
& WL & 0.537 & 0.546 & 0.543 & 0.542 \\
\hline \multirow{3}{*}{$D G$} & HL & 0.208 & 0.224 & 0.225 & 0.219 \\
& ZL & 0.257 & 0.249 & 0.274 & 0.260 \\
& WL & 0.463 & 0.451 & 0.436 & 0.450 \\
\hline
\end{tabular}

3.3.4. Shearing Stress-Strain Relationship of the Interface. Table 11 gives the maximum strain of the interface at failure. The WL samples have the highest strain values, while the ribbed samples show significant lower strain. The stressstrain curves are plotted in Figure 11. The HL rib sample has the largest shear modulus and the ZL rib sample is the second, while the WL sample has the lowest shear modulus. The ribs at the interface increase the mechanical friction of the sample but allow less relative movement, which is consistent with the previous results of interfacial bond-slip tests. 


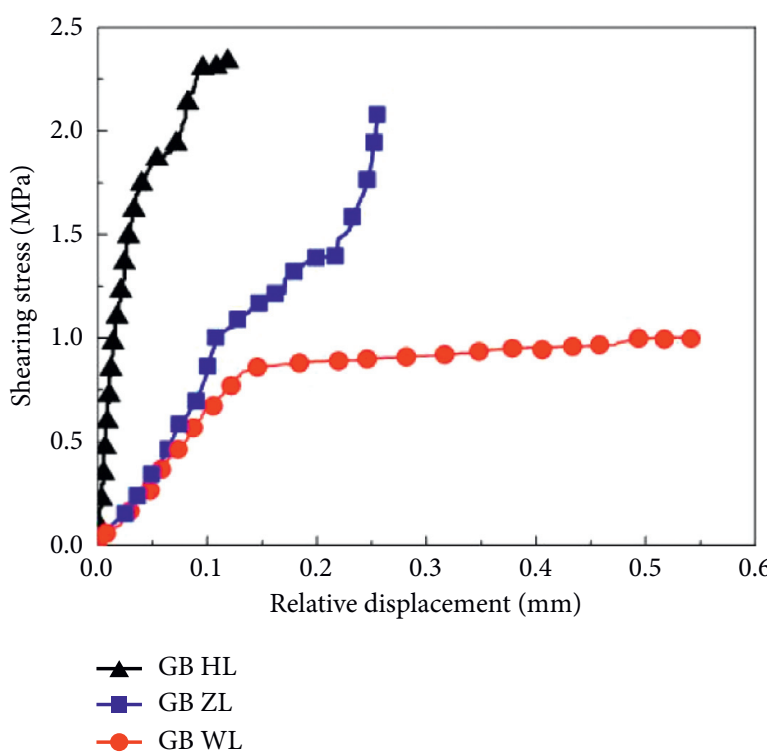

(a)

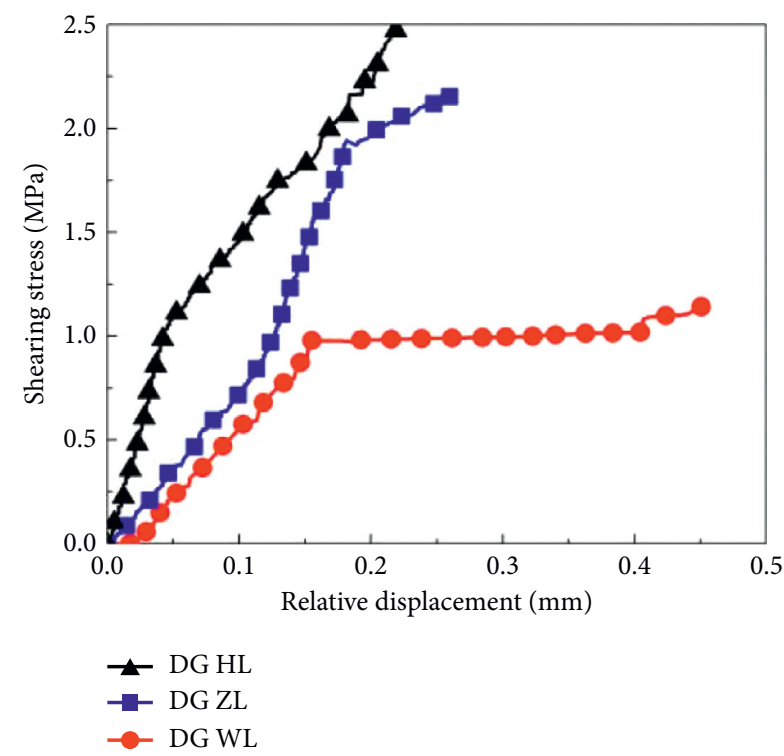

(b)

FIGURE 10: Relationship of the shearing stress over the relative displacement of the interface for composite samples with different ribs: (a) GB and (b) DG.

TABLE 11: Maximum strain of the interface at failure for composite samples with different ribs.

\begin{tabular}{lccccc}
\hline \multirow{2}{*}{ Cement plate } & \multirow{2}{*}{ Rib } & \multicolumn{4}{c}{ Maximum strain, $\mu \varepsilon$} \\
& & Sp1 & Sp2 & Sp3 & Average \\
\hline \multirow{3}{*}{$G B$} & HL & 169.3 & 172.1 & 182.1 & 174.5 \\
& ZL & 180.2 & 185.6 & 197.3 & 187.7 \\
& WL & 283.4 & 270.3 & 275.5 & 276.4 \\
\hline \multirow{3}{*}{$D G$} & HL & 143.5 & 149.2 & 148.6 & 147.1 \\
& ZL & 215.4 & 210.2 & 219.1 & 214.9 \\
& WL & 301.2 & 316.5 & 308.7 & 308.8 \\
\hline
\end{tabular}

3.4. Regression Expression for the Shear Strength of the Interface. The influence of the cement plate, concrete strength, and rib on the bonding performance of the interface has been studied using the push-out shear test in this paper. The regression analysis is then utilized to establish a mathematical relation between the shear strength and the 3 influencing factors, which is given in equation (1):

$$
\tau_{u}=0.638 \cdot \alpha \cdot \gamma \cdot\left(0.0217 f_{c u k}+0.261\right),
$$

where $\tau_{u}$ is the shear strength of the plate-concrete interface in $\mathrm{MPa} ; \alpha$ is a dimensionless factor representing the influence of the fiber mesh type ( $\alpha=1$ for the nonfiber cement plate, $\alpha=1.793$ for the GFRP cement plate, and $\alpha=1.572$ for the BFRP cement plate); $\gamma$ is also dimensionless expressing the influence of rib in the cement plate $(\gamma=1$ for WL sample, $\gamma=2.244$ for the sample with HL rib, and $\gamma=1.977$ for the ZL rib); $f_{c u k}$ is the standard cube compressive strength of the concrete.

The shear strength of the plate-concrete interface is computed using equation (1). Table 12 compares the calculated shear strength with the shear test results in this study. The ratio of the calculated value over the test result is also provided. It is found that in most cases the GB samples show slightly larger shear test results, while the DG samples slightly larger calculated shear strength. However, the ratios are very close to 1 , showing good agreement between the calculation equation and the shear test results. Therefore, equation (1) can be used to calculate the shear strength of the interface and provide good results, when the shear test is not available.

\section{A Constitutive Model for the Shear Strength- Relative Slip of the Interface}

According to the test results, all the samples show a linear relationship between the shear strength and the relative slip at the early loading stage. After reaching the maximum, the shear strength plateaus over a long relative displacement, but only for the samples with fiber-reinforced nonrib cement plates. However, for the nonfiber, nonrib samples, or the ribbed samples with no fiber-reinforced cement plates, the stress-slip curve only has the rising linear stage, and there is no obvious plastic deformation stage. These samples fail after the peak shear strength is reached and no plastic behavior is observed.

Figure 12 is used to express the relationship of the shearing stress and relative slip, where $\tau$ is the shearing stress in $\mathrm{MPa}$ and $S$ is the value of the relative slip in $\mathrm{mm}$. The shear stress of the interface increases linearly with the relative displace before it reaches the characteristic value of the relative displacement, $S_{0}$. The shear stress then maximizes at $\tau_{u}$ over the displacement range of $S_{0}<S<S_{u}$. The curve is divided into elastic $(\mathrm{OA})$ and plastic $(\mathrm{AB})$ sections according to the load-deformation characteristics. Note that only the linear growth Section OA is used for expressing the stressdisplacement relationship for the nonfiber and ribbed 


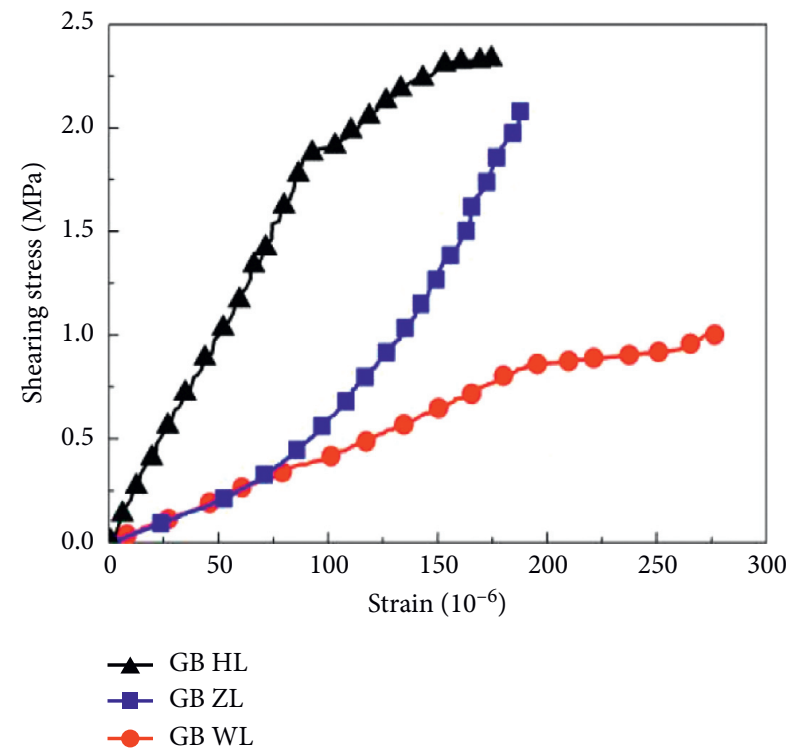

(a)

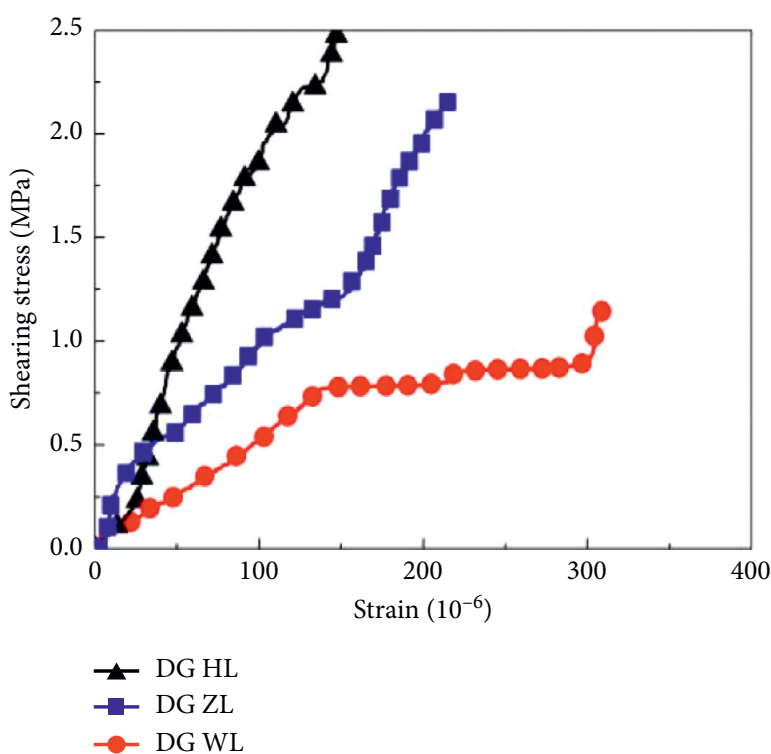

(b)

FIGURE 11: Stress-strain curves of the interface: (a) GB and (b) DG.

TABLE 12: Comparisons between calculated and test shear strength.

\begin{tabular}{lccc}
\hline Sample ID & Mean value of test results, MPa & Mean value of calculated results, MPa & Calculated results/test results \\
\hline GS C30 & 0.64 & 0.582 & 0.912 \\
GB C15 & 0.58 & 0.588 & 1.008 \\
GB C30 & 1.00 & 0.915 & 0.912 \\
GB C50 & 1.43 & 1.350 & 0.946 \\
GB HL & 2.33 & 2.053 & 0.881 \\
GB ZL & 2.08 & 2.053 & 0.987 \\
DG C15 & 0.56 & 0.671 & 1.198 \\
DG C30 & 1.14 & 1.043 & 0.912 \\
DG C50 & 1.36 & 1.540 & 1.130 \\
DG HL & 2.47 & 2.341 & 0.946 \\
DG ZL & 2.15 & 2.063 & 0.959 \\
\hline
\end{tabular}

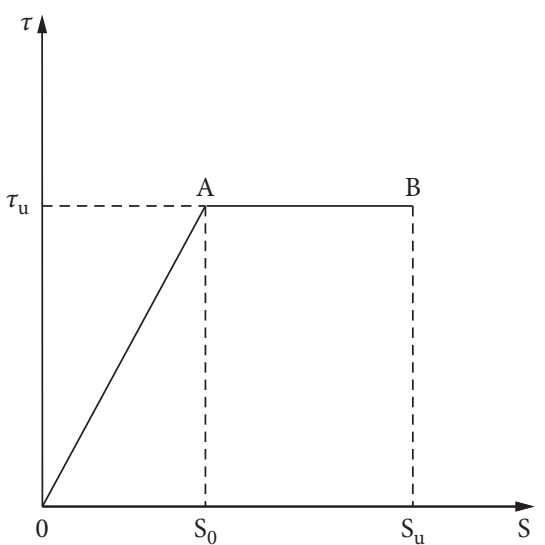

FIgURE 12: Constitutive model for the shearing stress-relative slip of the interface. samples. The load-deformation behavior of the samples using fiber-reinforced cement plates includes both sections.

4.1. Elastic Behavior of the Sample (Section OA). The experimental data are used to obtain the mathematical relationship between the shearing stress and relative slip using the regression method. Equation (2) gives the expression for the linear growth of stress over displacement in Section OA.

$$
\tau=2.409 \cdot \beta \cdot \eta \cdot\left(0.243 f_{c u k}-1.526\right) \cdot S, \quad\left(0<S \leq S_{0}\right),
$$

where $\tau$ is the shear stress of the plate-concrete interface; $\beta$ is the dimensionless factor concerning the influence of fiber mesh on the stress-slip relationship $(\beta=1$ for the nonfiber cement plate, $\beta=2.633$ for the GFRP cement plate, and 
$\beta=2.619$ for the BFRP cement plate); $\eta$ is a dimensionless parameter explaining the influence of rib in the cement plate ( $\eta=1$ for WL sample, $\eta=1.735$ for the sample with HL rib, and $\eta=1.304$ for the ZL rib); $f_{c u k}$ is the standard cube compressive strength of the concrete; $S$ is the relative slip of the plate-concrete interface $\left(0<S<S_{0}\right)$.

4.2. Plastic Behavior of the Sample (Section AB). In the following section of the curve, the shear stress of the interface maximizes at $\tau_{u}$ while the relative slip continues to increase. Equation (3) shows the relationship of shear stress over the relative slip.

$$
\tau=\tau_{u},\left(S>S_{0}\right)
$$

where $\tau_{u}$ is the shear strength of the interface. The shear strength can be obtained using equation (1).

4.3. Characteristic Value of the Relative Slip. $S_{0}$ is the characteristic value of relative slip referring to the amount of relative displacement when the shear stress reaches its peak value. Combining equations (1) and (2) yields the expression for $S_{0}$ :

$$
S_{0}=\frac{0.638 \cdot \alpha \cdot \gamma \cdot\left(0.0217 f_{c u k}+0.261\right)}{2.409 \cdot \beta \cdot \eta \cdot\left(0.243 f_{c u k}-1.526\right)} .
$$

In Figure 12, $S_{u}$ represents the maximum relative displacement when the samples fail completely. Note that, for the samples without plastic behavior, $S_{u}=S_{0}$ and is normally less than $0.3 \mathrm{~mm}$. For samples with plastic behavior, however, the relative slip characteristic values fall in the range of 0.45-0.55 mm.

It should be noted that the maximum concrete strength in this study uses the C50. Hence, the obtained equations above only apply for C50 concrete or less, and further research needs to be done for concrete strength grade higher than C50.

\section{Summaries and Conclusions}

This paper has analyzed the bonding performance of the plate-concrete interface by performing push-out shear test in the laboratory. A total of 3 groups of experiments have been conducted to assess the influence of the fiber mesh type, the concrete strength, and the inclusion of ribs in the cement plate. The failure characteristics of the sample, shear strength of the interface, and the relationship of load-deformation have been discussed for different samples. The regression method is adopted to compute the shear strength and the stress-displacement slip of the interface using the experimental data. The results provide guidance for improving the bonding performance of the interface. Important findings of this paper are listed as follows:

(1) Instead of brittle failure, the composite sample with fiber-reinforced cement plate shows plastic behavior following the elastic stage. The deformation performance of the interface is therefore improved by using the fiber-reinforced cement plate. These fiber- reinforced cement plates increase not only the buckling strength but also the shear stress of the plate-concrete interface. There is no appreciable difference between the GFRP and BFRP composite samples, although the GFRP samples have slightly larger shear strength, while the BFRP samples show slightly better deformation performance.

(2) The shear strength of the plate-concrete interface is improved when using higher strength of concrete. However, the maximum relative slip at failure is not increased with the increase of concrete strength. Composite samples with larger concrete strength (say C50) show good shear stiffness and plastic behavior following the elastic stage.

(3) The shear strength and shear stiffness of the interface are largely improved by setting ribs in the cement plate. However, the maximum relative slip of the interface is decreased for the rib samples. The layout of the rib is also influential to the interface bonding performance. The HL rib has larger shear strength and stiffness but lower maximum displacement.

(4) Good consistency is found between the stress-strain and stress-slip relationship of the interface. Therefore, the deformation characteristics of the interface can also be represented by measuring the strain data.

(5) The regression analysis gives the mathematical expression for the shear strength and the constitutive relationship of the stress-slip of the interface. The approximate elastic-perfectly plastic behavior is found for the samples using fiber-reinforced cement plates, while only linearly elastic behavior is observed for both nonfiber and rib samples.

\section{Abbreviations}

Sp1, Sp2, and Specimens 1, 2, and 3

Sp3:

$\tau:$

$\tau_{u}:$

$S:$

$S_{0}$ :

$S_{u}:$

$f_{t k}$ :

$\alpha:$

Shear stress of the plate-concrete interface Shear strength of the plate-concrete interface Relative bond-slip of the plate-concrete interface

o $\quad$ Characteristic value of relative bond-slip when the shear stress reaches maximum

$S_{u}$ Maximum relative bond-slip when the samples fail completely

$f_{t k}$ : Standard cube compressive strength of the concrete

$\alpha$ A dimensionless factor representing the influence of fiber mesh type on shear strength

$\gamma: \quad$ A dimensionless factor expressing the influence of rib on shear strength

$\beta$ : $\quad$ A dimensionless factor concerning the influence of fiber mesh on stress-slip relationship

$\eta$ : A dimensionless factor concerning the influence of rib on stress-slip relationship. 


\section{Data Availability}

The data used to support the findings of this study are included within the article.

\section{Conflicts of Interest}

The authors declare no conflicts of interest.

\section{Acknowledgments}

This research was supported by the Key Science and Technology Projects in Transportation Industry (2018-MS2051) and the Excellent Research Team of North China University of Technology (107051360021XN083/019). The authors are grateful for Dr. Gaofeng Song's help in improving English writing.

\section{References}

[1] L.-P. Ye and F. Peng, "Applications and development of fiberreinforced polymer in engineering structures," China Civil Engineering Journal, vol. 39, no. 3, pp. 24-36, 2006.

[2] X. Fan, J. Liu, S. Hu, and J. Lu, "Experimental study on dynamic mechanical properties of concrete beams strengthened with CFRP at different loading rates," Journal of Building Structures, vol. 41, no. 7, pp. 201-206, 2020.

[3] G. Alaim, A. Valenza, D. Enea, and V. Fiore, "The durability of basalt fibres reinforced polymer (BFRP) panels for cladding," Materials \& Structures, vol. 49, no. 6, pp. 2053-2064, 2016.

[4] Y.-X. Yang, W. Chen, and M.-S. Ma, "Durability of basalt fiber sheets under wet-dry cycling in seawater," Industrial Construction, vol. 47, no. 4, pp. 5-8, 2010.

[5] A. K. El-Sayed, E. El-Salakawy, and B. Benmokrane, "Shear strength of FRP reinforced concrete beams without transverse reinforcement," ACI Structural Journal, vol. 3, no. 2, pp. 235-243, 2006.

[6] Z. F. Chen, L. L. Wan, S. Lee et al., "Evaluation of CFRP, GFRP and BFRP material systems for the strengthening of RC slabs," Journal of Reinforced Plastics and Composites, vol. 27, no. 12, pp. 1233-1243, 2008.

[7] T. Ma, P. Jin-Long, and W. Hong-Li, "Experimental study of bond behavior between CFRP and concrete under cyclic loading," Building Structure, vol. 45, no. 19, pp. 15-18, 2013.

[8] G.-M. Chen, D. Liu, L. Yun-Lei, L. Shi-Wei, C. Jian-Fei, and $\mathrm{X}$. Hao-Bin, "Bond behavior between shear strengthening FRP and concrete: an experimental study," Engineering $\mathrm{Me}$ chanics, vol. 32, no. 7, pp. 164-175, 2015.

[9] A. Nanni, B. Miller, and L. D. Lorenzis, "Bond of fiberreinforced polymer laminates to concrete," ACI Materials Journal, vol. 98, no. 3, pp. 256-264, 2001.

[10] K. Nakaba, T. Kanakubo, T. Furuta, and H. Yoshizawa, "Bond behavior between fiber-reinforced polymer laminates and concrete," ACI Structural Journal, vol. 98, no. 3, pp. 359-367, 2001.

[11] L. Rong, T. Jin-Guang, and Y. Qing-Rui, "Experimental study on bond behavior of NSM CFRP strips-concrete interface," Industrial Construction, vol. 42, no. 8, pp. 31-34, 2005.

[12] R. J. Gravina, S. A. Hadigheh, and S. Setunge, "Interfacial bond strength of resin-impregnated fibre-reinforced polymer laminates bonded to concrete using vacuum and heat: experimental study," Australian Journal of Structural Engineering, vol. 15, no. 2, pp. 189-201, 2014.
[13] Y. Zhou, X. Wang, L. Sui et al., "Effect of mechanical fastening pressure on the bond behaviors of hybrid-bonded FRP to concrete interface," Composite Structures, vol. 204, 2018.

[14] C. Chen, L. Xue, X. Wang et al., "Effect of transverse groove on bond behavior of FRP-concrete interface: experimental study, image analysis and design," Composites Part B, vol. 161, 2019.

[15] Z. Wang, S. Shen, Y. Ju, and M. Shao, "Research progress on durability of bonding interface of FRP cloth reinforced structure," Composite Materials Science and Engineering, vol. 47, no. 7, pp. 117-122, 2020.

[16] S. Wang, Y. Yao, and H. Lei, "Durability of FRP-high strength concrete adhesive joints under aggressive exposure conditions and loads," Journal of Disaster Prevention and Mitigation Engineering, vol. 37, no. 1, pp. 127-133, 2017.

[17] X.-Y. Lin and S.-Y. Cao, "Study on bond behavior of intercrack CFRP and concrete in beams strengthened with fibers," Engineering Mechanics, vol. 25, no. 11, pp. 149-155, 2008.

[18] S.-K. Woo and Y. Yun, "Experimental study on interfacial behavior of CFRP-bonded concrete," KSCE Journal of Civil Engineering, vol. 14, no. 3, pp. 385-393, 2010.

[19] H. A. Baky, U. A. Ebead, and K. W. Neale, "Nonlinear micromechanics-based bond-slip model for FRP/concrete interfaces," Engineering Structures, vol. 39, no. 6, pp. 11-23, 2003.

[20] J.-G. Dai, W. Y. Gao, and J. G. Teng, "Bond-slip model for FRP laminates externally bonded to concrete at elevated temperature," Journal of Composites for Construction, vol. 17, no. 2, pp. 217-228, 2013.

[21] X.-L. Wang, Y. Jia-Jia, H.-Y. Sun, K. Li, and X.-D. Kang, "Experimental study on bond-slip model for CFRP-concrete interface based on beam test," Journal of Disaster Prevention and Mitigation Engineering, vol. 34, no. 3, pp. 314-319, 2014.

[22] D.-Y. Gao, H.-T. Zhu, and J.-J. Xie, "The constitutive models for bond slip relation between FRP rebars and concrete," Industrial Construction, vol. 40, no. 7, pp. 41-43, 2003.

[23] X. Lu, L. Ye, J. Teng, and J. Zhuang, "Bond-slip model for FRP-to-concrete interface," Journal of Building Structures, vol. 26, no. 4, pp. 10-18, 2005.

[24] H. Ko, S. Matthys, A. Palmieri, and Y. Sato, "Development of a simplified bond stress-slip model for bonded FRP-concrete interfaces," Construction and Building Materials, vol. 68, no. 4, pp. 142-157, 2014.

[25] H. Qing-duo, Y.-L. Wang, J.-L. Hou, and O. Jin-Ping, "Bondslip constitutive model between GFRP/steel wire composite rebars and concrete," Engineering Mechanics, vol. 26, no. 5, pp. 62-72, 2009.

[26] S. Xiao-Ruan, J.-L. Gao, and J.-Y. Qu, "Experimental study on physical and mechanical properties of GRC formwork," Journal of Beijing University of Technology, vol. 34, no. 7, pp. 708-713, 2008. 